\title{
L-Lactic Acid Production Using Engineered Saccharomyces cerevisiae with Improved Organic Acid Tolerance
}

\author{
Byeong-Kwan Jang ${ }^{1}$, Yebin Ju ${ }^{1}{ }^{\mathbb{D}}$, Deokyeol Jeong ${ }^{1}$, Sung-Keun Jung ${ }^{1}$, Chang-Kil Kim ${ }^{2}$, Yong-Suk Chung ${ }^{3, * \mathbb{C}}$ \\ and Soo-Rin Kim $1, * \mathbb{D}$ \\ 1 Major in Food Application Technology, School of Food Science and Biotechnology, \\ Kyungpook National University, Daegu 41566, Korea; byeonggwan_jang@naver.com (B.-K.J.); \\ jyb52795279@gmail.com (Y.J.); dyj@knu.ac.kr (D.J.); skjung04@knu.ac.kr (S.-K.J.) \\ 2 Department of Horticulture, Kyungpook National University, Daegu 41566, Korea; ckkim@knu.ac.kr \\ 3 Department of Plant Resources and Environment, Jeju National University, Jeju 63243, Korea \\ * Correspondence: yschung@jejunu.ac.kr (Y.-S.C.); soorinkim@knu.ac.kr (S.-R.K.)
}

Citation: Jang, B.-K.; Ju, Y.; Jeong, D.; Jung, S.-K.; Kim, C.-K.; Chung, Y.-S.; Kim, S.-R. L-Lactic Acid Production Using Engineered Saccharomyces cerevisiae with Improved Organic Acid Tolerance. J. Fungi 2021, 7, 928. https://doi.org/10.3390/jof7110928

Academic Editors: Isabel Sa-Correia and Naseem A. Gaur

Received: 30 September 2021 Accepted: 30 October 2021 Published: 31 October 2021

Publisher's Note: MDPI stays neutral with regard to jurisdictional claims in published maps and institutional affiliations.

Copyright: (c) 2021 by the authors. Licensee MDPI, Basel, Switzerland. This article is an open access article distributed under the terms and conditions of the Creative Commons Attribution (CC BY) license (https:/ / creativecommons.org/licenses/by/ $4.0 /)$.

\begin{abstract}
Lactic acid is mainly used to produce bio-based, bio-degradable polylactic acid. For industrial production of lactic acid, engineered Saccharomyces cerevisiae can be used. To avoid cellular toxicity caused by lactic acid accumulation, $\mathrm{pH}$-neutralizing agents are used, leading to increased production costs. In this study, lactic acid-producing S. cerevisiae BK01 was developed with improved lactic acid tolerance through adaptive laboratory evolution (ALE) on $8 \%$ lactic acid. The genetic basis of BK01 could not be determined, suggesting complex mechanisms associated with lactic acid tolerance. However, BK01 had distinctive metabolomic traits clearly separated from the parental strain, and lactic acid production was improved by $17 \%$ (from $102 \mathrm{~g} / \mathrm{L}$ to $119 \mathrm{~g} / \mathrm{L}$ ). To the best of our knowledge, this is the highest lactic acid titer produced by engineered $S$. cerevisiae without the use of $\mathrm{pH}$ neutralizers. Moreover, cellulosic lactic acid production by BK01 was demonstrated using acetate-rich buckwheat husk hydrolysates. Particularly, BK01 revealed improved tolerance against acetic acid of the hydrolysates, a major fermentation inhibitor of lignocellulosic biomass. In short, ALE with a high concentration of lactic acid improved lactic acid production as well as acetic acid tolerance of BK01, suggesting a potential for economically viable cellulosic lactic acid production.
\end{abstract}

Keywords: lactate dehydrogenase; whole-genome sequencing; Saccharomyces cerevisiae; lignocellulosic biomass; polylactic acid

\section{Introduction}

Lactic acid is an organic acid widely used in the food, pharmaceutical, textile, and chemical industries, especially for the production of polylactic acid [1,2], a biodegradable and compostable bioplastic [3-5]. Lactic acid is produced by microbial fermentation such as natural lactic acid producer, lactic acid bacteria (LAB) [6,7]. However, lactic acid production by natural producers is limited due to low maximum titers and optical isomers [8]. Additionally, LAB is not considered as a suitable host for industrial fermentations due to phage contamination issues and high nutritional requirements $[9,10]$.

Engineered Saccharomyces cerevisiae expressing a heterologous lactate dehydrogenase gene $(l d h)$ is a promising workhorse for industrial lactic acid production $[11,12]$. Various metabolic engineering approaches have been performed to improve lactic acid production by the yeast [13]. Expression of multiple copies of $l d h$ genes increased lactate dehydrogenase expression levels and lactic acid production [14-18]. Additionally, rational engineering strategies have been used to convert more pyruvate to lactic acid by removing genes in the ethanol pathway, including pyruvate decarboxylase genes (PDC1, PDC2, PDC5, and $P D C 6)$ and alcohol dehydrogenase genes ( $A D H 1, A D H 5$, and $A D H 6)$, which compete with the newly introduced lactic acid pathway $[15,17-21]$. 
Lactic acid causes cellular toxicity at near its pKa value (3.86) [22]. The use of neutralizing agents such as calcium hydroxide $\left(\mathrm{Ca}(\mathrm{OH})_{2}\right)$ and calcium carbonate $\left(\mathrm{CaCO}_{3}\right)$ during lactic acid fermentation therefore helps to avoid the toxicity and the accumulation of a high concentration of lactic acid [23]. However, when the fermentation is completed, the fermentation medium should be acidified for purification of lactic acid, which results in gypsum $\left(\mathrm{CaSO}_{4}\right)$ formation and increased production costs $[24,25]$. Therefore, development of a lactic acid-tolerant strain is one of the most important strain engineering goals for industrial lactic acid production $[12,17,18,26]$.

In this study, we performed adaptive laboratory evolution (ALE) of lactic acidproducing S. cerevisiae strain in a high concentration of lactic acid to develop an evolved mutant with improved tolerance against lactic acid. Using genome sequencing and metabolomic profiling, the evolved mutant was characterized. Using buckwheat husk hydrolysates, we demonstrated cellulosic lactic acid production by the evolved strain.

\section{Materials and Methods}

\subsection{Strain Construction}

Lactic acid-producing S. cerevisiae SR8LDH strain (Table 1) was developed in a previous study $[8,27,28]$. Briefly, the $l d h$ gene from Lactobacillus acidophilus ATCC4356 expressed under the control of the PGK1 promoter and the expression cassette were genomeintegrated into the xylose-fermenting S. cerevisiae SR8 strain [29].

Table 1. Strains used in this study.

\begin{tabular}{|c|c|c|c|}
\hline Description & Strain & Genotype & Reference \\
\hline Background strain & SR8 & $\begin{array}{l}\text { S. cerevisiae D } 452-2 \text { expressing the xylose oxidoreductase pathway derived } \\
\text { from Pichia stipitis (XYL1, XYL2, and XYL3), Dald6, adaptive laboratory } \\
\text { evolution on xylose }\end{array}$ & [29] \\
\hline Parental strain & SR8LDH & $\begin{array}{l}\text { Xylose-metabolizing SR8 expressing the } l d h \text { gene from Lactobacillus } \\
\text { acidophilus }\end{array}$ & [8] \\
\hline \multirow[t]{4}{*}{ Evolved strain } & BK01 & $\begin{array}{l}\text { SR8LDH strain evolved on complex medium containing } 20 \mathrm{~g} / \mathrm{L} \text { glucose and } \\
8 \% \text { lactic acid }\end{array}$ & This study \\
\hline & BK_D1 & BK01 sypt7 & This study \\
\hline & BK_D2 & BK01 $\Delta y o l 159 c-a$ & This study \\
\hline & BK_D3 & BK01 $\Delta y p t 7 / \Delta y o l 159 c-a$ & This study \\
\hline \multirow{6}{*}{$\begin{array}{l}\text { Reverse-engineered } \\
\text { strains }\end{array}$} & LDH_R1 & SR8LDH m YPT7 (533G>A) & This study \\
\hline & LDH_R2 & SR8LDH m YOL159C- $A(172 C>A)$ & This study \\
\hline & LDH_R3 & SR8LDH mYPT7/mYOL159C-A & This study \\
\hline & LDH_D1 & SR8LDH $\Delta y p t 7$ & This study \\
\hline & LDH_D2 & SR8LDH $\Delta y o l 159 c-a$ & This study \\
\hline & LDH_D3 & SR8LDH $\Delta y p t 7 / \Delta y o l 159 c-a$ & This study \\
\hline
\end{tabular}

\section{2. $A L E$}

ALE was conducted in $100 \mathrm{~mL}$ Erlenmeyer flasks with $20 \mathrm{~mL}$ complex medium $(10 \mathrm{~g} / \mathrm{L}$ yeast extract and $20 \mathrm{~g} / \mathrm{L}$ peptone) containing $20 \mathrm{~g} / \mathrm{L}$ glucose and $8 \%(w / v)$ lactic acid (pH 3.1). The initial cell density was $0.05 \mathrm{~g}$ dry cell weight (DCW)/L. When cells entered the stationary phase, $1 \%$ culture was transferred to new media. Serial subcultures were performed until there was no change in growth rate. From the final culture, six colonies were isolated and evaluated for growth rate in complex medium containing $20 \mathrm{~g} / \mathrm{L}$ glucose and $8 \%$ lactic acid. 


\subsection{Fermentation Studies}

A single colony was pre-cultivated in $5 \mathrm{~mL}$ complex medium containing $20 \mathrm{~g} / \mathrm{L}$ glucose at $30^{\circ} \mathrm{C}$ and $250 \mathrm{rpm}$ for $24 \mathrm{~h}$. Fermentations were performed in $100 \mathrm{~mL}$ Erlenmeyer flasks with $20 \mathrm{~mL}$ complex medium containing $20 \mathrm{~g} / \mathrm{L}$ or $200 \mathrm{~g} / \mathrm{L}$ glucose (pH 5.7) under $30{ }^{\circ} \mathrm{C}$, oxygen-limited conditions $(80 \mathrm{rpm})$. All fermentations were independently performed in triplicate without $\mathrm{pH}$ control.

\subsection{Genome Sequencing and Single-Nucleotide Polymorphism (SNP) Analysis}

Genomic DNA from the cells was extracted using YeaStar DNA kits (Zymo Research, Irvine, CA, USA) and purified using Genomic DNA purification kits (Promega, Madison, WI, USA) for genome sequencing. DNA quantity and quality were confirmed using the Quant-It PicoGreen dsDNA assay kit (Invitrogen, Waltham, MA, USA) and agarose gel electrophoresis, respectively. Barcoded library construction and genome sequencing using Illumina Miseq instrumentation (Illumina, San Diego, CA, USA) were performed at CHUNLAB (CHUNLAB, Seoul, Korea). Barcoded shotgun genomic DNA libraries were constructed using the TruSeq Sample Prep Kit, following the manufacturer's instructions (Illumina), and were subjected to 300 base pair (bp) paired-end sequencing by Illumina Miseq. Sequencing raw data were deposited in the Sequence Read Archive and are available at the NCBI BioProject PRJNA690663. SNP analyses were performed using CLC Genomics Workbench version 5.1 (QIAGEN, Hilden, Germany). Reads were trimmed based on quality scores from default program settings. The reads were mapped to an S288C yeast reference sequence (obtained from Genbank) to identify SNPs in SR8LDH and BK01. Next, unique, non-synonymous SNPs in BK01 relative to SR8LDH were identified (Table S1).

\subsection{SNP Confirmation by Sanger Sequencing}

The genes with potential SNPs were amplified using Q5®High-Fidelity DNA Polymerase (New England Biolabs, Ipswich, MA, USA) according to manufacturer's instructions. We used $20 \mathrm{ng} / \mu \mathrm{L}$ genomic DNA from SR8LDH and BK01 as template DNA. Amplified products were purified using Geneall ExpinTM PCR SV kit (Geneall, Seoul, Korea). Sanger sequencing was performed to confirm predicted SNPs (Cosmogenetech, Seoul, Korea).

\subsection{Reverse Engineering}

Reverse engineering was performed by introducing two confirmed SNPs, $\mathrm{m} Y P T 7$ (533G $>\mathrm{A})$ and $\mathrm{m} Y O L 159 \mathrm{C}-\mathrm{A}(172 \mathrm{C}>\mathrm{A})$, into the parental strain (SR8LDH), as described previously using CRISPR-Cas9 [30]. Additionally, YPT7, YOL159C-A, and both genes were deleted equally from SR8LDH and BK01, respectively. Briefly, strains expressing the pRS41N-Cas9 plasmid [31] were transformed with the guide RNA plasmids (Table S2) and the donor DNA fragments prepared by using primers listed in Table S3. Exceptionally, the mYOL159C- $A$ allele could not be introduced directly using CRISPR-Cas9. Therefore, the wild copy of $Y O L 159 C-A$ was deleted, and the resulting knockout mutant was transformed to introduce the mYOL159C-A allele, amplified from the genomic DNA of BK01. Using the primers in Table $\mathrm{S} 3$ and sanger sequencing, the reverse-engineered strains were confirmed as the SR8LDH_mYPT7 strain (LDH_R1), SR8LDH_mYOL159C-A strain (LDH_R2) strain, and the SR8LDH_mYPT7/mYOL159C-A strain (LDH_R3) (Table 1).

\subsection{Cell growth, $p H$, and Extracellular Metabolite Analysis}

Cell density was presented by DCW, which was converted from the absorbance at $600 \mathrm{~nm}$ using a spectrophotometer (OPTIZEN NANO Q, Mecasis, Daejeon, Korea) $\left(\mathrm{OD}_{600}\right.$ $1=0.47 \mathrm{~g} \mathrm{DCW} / \mathrm{L}$ ). A pH meter (SevenCompact $\mathrm{pH}$ meter S220, Mettler Toledo, Columbus, $\mathrm{OH}, \mathrm{USA}$ ) was used for the $\mathrm{pH}$ determination of hydrogen ion concentration. Glucose, L-lactic acid, and ethanol concentrations during fermentation were analyzed, as previously described [32]. Briefly, serially diluted cultures were centrifuged at 13,000 rpm for $10 \mathrm{~min}$ at $4{ }^{\circ} \mathrm{C}$. Supernatants were analyzed by high performance liquid chromatography (1260 Series, 
Agilent Technologies, CA, Santa Clara, USA) equipped with a refractive detector, connected to a Rezex ROA-Organic Acid H+ $(8 \%)$ column (Phenomenex Inc., Torrance, CA, USA). The column was eluted in $0.005 \mathrm{~N} \mathrm{H}_{2} \mathrm{SO}_{4}$ at a flow rate of $0.6 \mathrm{~mL} / \mathrm{min}$ at $50{ }^{\circ} \mathrm{C}$. The retention time for glucose, ethanol, and lactic acid was $4.938 \mathrm{~min}, 10.873 \mathrm{~min}$, and $6.960 \mathrm{~min}$, respectively.

\subsection{Intracellular Metabolite Extraction and Derivatization}

Cell quenching, intracellular metabolite extraction, and derivatization for intracellular metabolite analyses were performed as previously described [33,34]. Briefly, $5 \mathrm{~mL}$ of cell culture at the mid-exponential growth phase was quickly injected and quenched in $25 \mathrm{~mL}$ $60 \%(v / v)$ cold methanol with $10 \mathrm{mM}$ HEPES ( $\mathrm{pH} 7.1$ ) at $-40{ }^{\circ} \mathrm{C}$. Quenched cells were centrifuged, and supernatants were discarded. Then, $1 \mathrm{~mL}$ of $75 \%(v / v)$ boiling ethanol with $10 \mathrm{mM}$ HEPES ( $\mathrm{pH}$ 7.1) was added to the quenched cell pellet and resuspended. The mixture was incubated at $-80^{\circ} \mathrm{C}$ for $5 \mathrm{~min}$, then centrifuged, and extracted intracellular metabolites (supernatant) were collected. Extracts were vacuum-dried for $4 \mathrm{~h}$ using a speed vacuum concentrator (VC-96R, TAITEC, Saitama, Japan). Dried intracellular extracts underwent methoxyamination with $10 \mu \mathrm{L}$ methoxyamine hydrochloride in pyridine (40 mg/mL, Sigma-Aldrich, St. Louis, MO, USA) and incubated at $30^{\circ} \mathrm{C}$ for $90 \mathrm{~min}$. For silylation, $40 \mu \mathrm{L}$ N-Methyl-N-trimethylsilyl-trifluoroacetamide (Sigma-Aldrich) was added to samples and incubated at $37^{\circ} \mathrm{C}$ for $30 \mathrm{~min}$.

\subsection{Intracellular Metabolite Analysis and Identification Using Gas Chromatography-Mass Spectroscopy (GC-MS)}

GC-MS analysis was performed as previously described with some modifications [35]. An Agilent 6890 GC (Agilent Technologies) coupled to an Agilent 5973N MSD (Agilent Technologies) was used. One microliter of the derivatized sample was injected through an Agilent 7683 ALS (Agilent Technologies) into the GC in splitless mode. Samples were separated on an RTX-5Sil MS column $(30 \mathrm{~m} \times 0.25 \mathrm{~mm} \times 0.25 \mu \mathrm{m}$, Restek, Bellefonte, PA, USA). The initial oven temperature was $50^{\circ} \mathrm{C}$ for $1 \mathrm{~min}$ and then ramped at $20^{\circ} \mathrm{C} / \mathrm{min}$ to a final temperature of $330{ }^{\circ} \mathrm{C}$ and held for $5 \mathrm{~min}$. Helium was used as a carrier gas at $0.7 \mathrm{~mL} / \mathrm{min}$. The temperatures of the ion source and transfer line were set to $230^{\circ} \mathrm{C}$ and $250{ }^{\circ} \mathrm{C}$, respectively. An electron impact of $70 \mathrm{eV}$ was used for ionization. The mass selective detector was operated in scan mode with a mass range of 50-650 m/z.

\subsection{Data and Statistical Analysis}

To identify metabolites, raw data files were converted to netCDF format using Agilent Chemstation software (Agilent Technologies and the analysis base file converter; https: //www.reifycs.com/AbfConverter/). Converted ABF format files were analyzed using MS-DIAL software (version: 4.60, Riken, Kanagawa, Japan) [36,37]. An average peak width of 20 scans and a minimum peak height of 1000 amplitudes were used for peak detection. A Sigma window value of 0.5 and electron ionization (EI) spectra cut-off of 10 amplitudes were used for deconvolution. For identification settings, the retention index tolerance was 2000 , the $\mathrm{m} / \mathrm{z}$ tolerance was $0.5 \mathrm{Da}$, the EI similarity cutoff was $70 \%$, and the identification score cutoff was $80 \%$. In the alignment parameter setting process, the retention time factor was 0.5 . The peak intensity of identified metabolites was normalized by cell concentration (g DCW/L) for each sample. Statistica software (version 7.1, StatSoft, NYC, NY, USA) was used for principal component analysis (PCA), which is a multivariate analysis method and a useful statistical technique for reducing the dimensions of a dataset containing a large number of variables without the prerequisite knowledge of the dataset, by transforming original variables into abbreviated principal components (PCs) [38].

\subsection{Lignocellulosic Hydrolysate Preparation and Simultaneous Saccharification and Fermentation (SSF) of the Engineered Yeast Strain}

Buckwheat (Fagopyrum esculentum var. Daesan) was cultivated in Jeju Island (Korea) and harvested at the end of June in 2020. Buckwheat husks were separated from grains 
and dried at $60{ }^{\circ} \mathrm{C}$ for $24 \mathrm{~h}$. The dried buckwheat husk samples were milled and stored at $-80{ }^{\circ} \mathrm{C}$ until use. Buckwheat husk hydrolysate was prepared as previously described [39]. Four grams of buckwheat husk powder was mixed with $1 \%(w / v) \mathrm{H}_{2} \mathrm{SO}_{4}$ solution, treated at $121^{\circ} \mathrm{C}$ for $30 \mathrm{~min}$ by autoclave (MLS-3781L, Panasonic, Osaka, Japan), and neutralized using $7.5 \mathrm{~N} \mathrm{NaOH}$ solution until pH 6.5. SSF of the buckwheat husk hydrolysates was performed as previously described [8,39]. For cellulase, Cellic®CTec2 (Novozymes, Bagsværd, Denmark) was used. A total of 40 filter paper cellulase units (FPU/g biomass) and $10 \mathrm{~g}$ DCW/L pre-cultured cells were added to the pretreated buckwheat husk hydrolysates, and the final volume was adjusted to $20 \mathrm{~mL}$ for $20 \%(w / v)$ solid SSF. Each fermentation was performed in $100 \mathrm{~mL}$ Erlenmeyer flasks for $24 \mathrm{~h}$ at $30^{\circ} \mathrm{C}$ at $130 \mathrm{rpm}$ under oxygen-limited conditions in biological triplicates.

\section{Results and Discussion}

\subsection{ALE of Lactic Acid-Producing S. cerevisiae in a High Concentration of Lactic Acid}

To improve lactic acid tolerance of the lactic acid-producing S. cerevisiae SR8LDH strain, cells were subjected to ALE by serial sub-cultures in complex medium containing a high concentration of lactic acid (8\%), which critically limits cell growth [40,41]. During the first culture, a significantly long lag phase $(216 \mathrm{~h})$ was observed (Figure $1 \mathrm{~A})$. However, the lag time was greatly reduced in the second culture, with no more reduction in subsequent cultures. We isolated six colonies from the final culture and evaluated their lactic acid tolerance (Figure 1B). The most representative colony (BK01) was selected, and the improved lactic acid tolerance was confirmed again by the spotting assay (Figure 1C). SR8LDH and BK01 showed no difference in growth on complex agar medium containing $20 \mathrm{~g} / \mathrm{L}$ glucose and $6 \%$ lactic acid. However, when lactic acid concentration was increased to $8 \%$, BK01 showed better growth than SR8LDH.

In previous studies, ALE was also successfully applied to develop lactic acid-tolerant S. cerevisiae $[17,18,42]$. For the evolution conditions, lactic acid concentration gradually increased from $1 \%$ to $4 \%$ during 11 subcultures, and the evolved mutant showed no growth reduction with $1 \%$ lactic acid $[17,18]$. In another study, evolution was performed under $8 \%$ lactic acid conditions, and the resulting strain showed a maximum tolerance to $6 \%$ lactic acid and not growth on $8 \%$ lactic acid [42]. In the present study, BK01 was able to grow on $8 \%$ lactic acid, which was a higher tolerance than the previously reported strains.

\subsection{Genome Sequencing of the Evolved Strain and Reverse Engineering}

To determine the genetic basis of the improved lactic acid tolerance, genome resequencing of the parental (SR8LDH) and the evolved (BK01) strains was performed, and 24 SNPs were identified, as listed in Table S1. Sanger sequencing of the potential SNPs was able to confirm two SNPs in the mYPT7 (533G $>$ A) and mYOL159C-A (172C $>\mathrm{A})$ genes. For reverse engineering, the two SNPs were introduced to SR8LDH, resulting in LDH_R1 (mYPT7), LDH_R2 (mYOL159C-A), and LDH_R3 (mYPT7 and mYOL159C-A) (Table 1). However, those reverse-engineered strains did not show tolerance to lactic acid (Figure 1D). Based on the assumption of the loss of function mutations on the two genes (YPT7, and YOL159C-A) in BK01, those genes were deleted in SR8LDH, resulting in LDH_D1, LDH_D2, and LDH_D3 strains (Table 1), and those deletion mutants did not show tolerance to lactic acid (Figure S1). However, when any of the identified mutant alleles (mYPT7 and $\mathrm{m} Y O L 159 \mathrm{C}-A$ ) were deleted in BK01, the resulting strains (BK_D1, BK_D2, and BK_D3 in Table 1) lost the lactic acid tolerance. These results suggested that both $\mathrm{m} Y P T 7$ and $\mathrm{m} Y O L 159 \mathrm{C}-A$ are associated with the improved lactic acid tolerance of BK01 and that there are other genetic factors required for the tolerance, which could not be identified by simple SNP identification.

Among previously reported evolved S. cerevisiae strains on lactic acid, one strain was genome-sequenced, and the SNPs were identified in five different genes (BSD2, ERF2, CIT2, NCL1, and SUR1) [17]. Reverse engineering of the individual and combinatorial mutations discovered that the combination of erf $2 \Delta$ and mSUR1 improves lactic acid tolerance to 
some degree. However, the reverse-engineered strain showed significantly lower lactic acid tolerance than the evolved strain. This result suggests that lactic acid tolerance is a complex trait with multiple genetic factors.
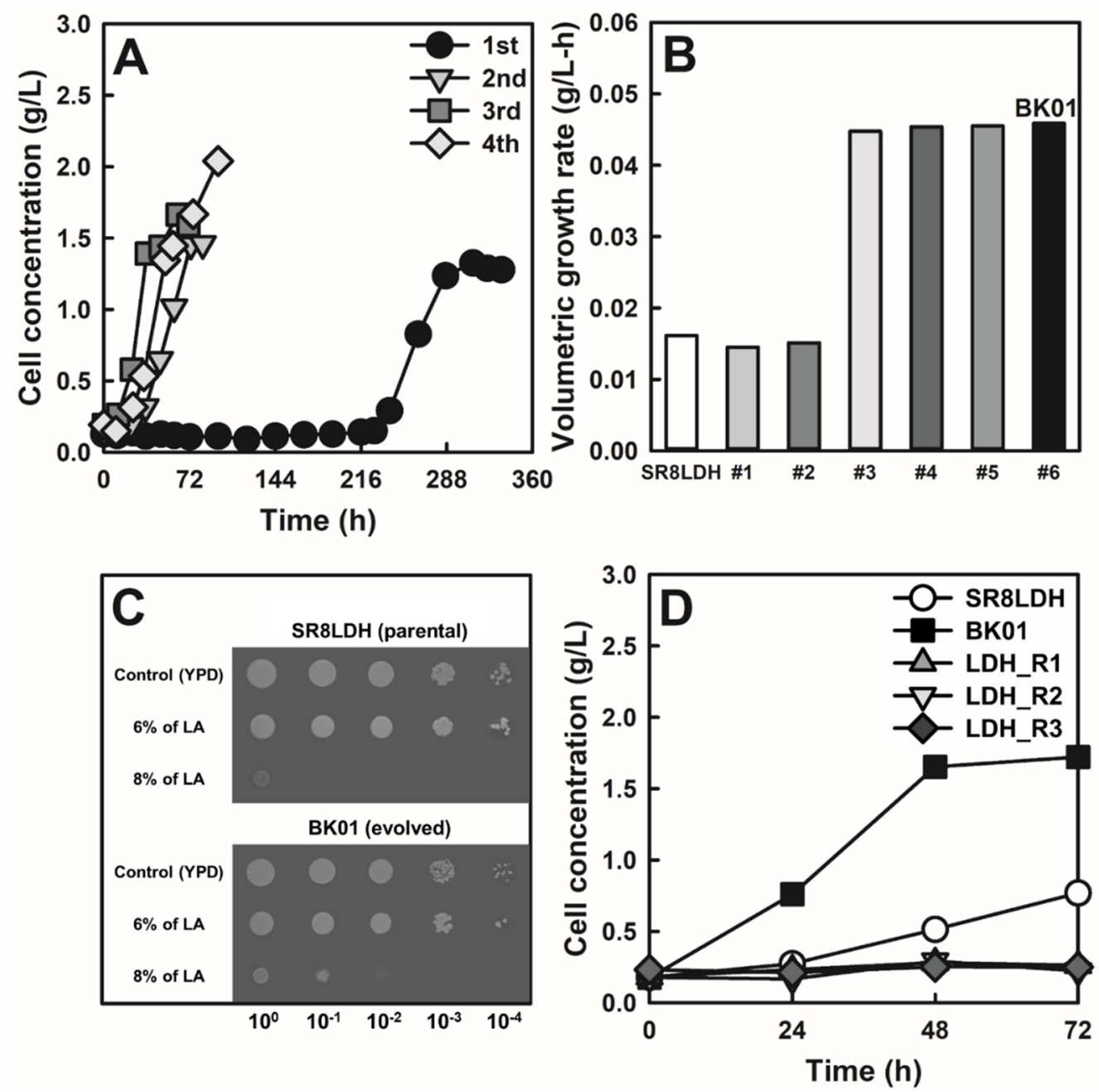

Figure 1. Adaptive laboratory evolution (ALE) of the lactic acid-producing S. cerevisiae SR8LDH strain in a high concentration of lactic acid and isolation of the lactic acid-tolerant BK01 strain. (A) Cell concentrations were monitored during four consecutive subcultures of SR8LDH in complex medium containing $20 \mathrm{~g} / \mathrm{L}$ glucose and 8\% lactic acid. (B) Comparison of volumetric growth rates (g/L-h) of six evolved SR8LDH strains (\#1-\#6) in 8\% lactic acid and the selection of a representative evolved strain, BK01 (\#6). (C) Spotting assay of SR8LDH and BK01 on complex agar medium containing $20 \mathrm{~g} / \mathrm{L}$ glucose and $0 \%, 6 \%$, and 8\% lactic acid. (D) Growth rate comparisons of SR8LDH, BK01, and the reverse-engineered strains (described in Table 1) in complex medium containing $20 \mathrm{~g} / \mathrm{L}$ glucose and $8 \%$ lactic acid. All experiments were conducted under oxygen-limited conditions ( $80 \mathrm{rpm})$, with an initial cell concentration of $0.05 \mathrm{~g}$ DCW/L.

\subsection{Metabolomic Analysis of the Evolved Strain}

To identify metabolomic differences between SR8LDH and BK01, fresh grown cells without lactic acid stress were used for the extraction of intracellular metabolites and analysis by GC-MS. Based on PCA, the intracellular metabolites of SR8LDH and BK01 were clearly separated by PC1, as shown in a score plot (Figure 2A), and the top 10 metabolites that were the most significantly different were classified by PC1, as shown in a loading plot (Figure 2B). Among those significantly different metabolites (Table S4), galactonic acid, inositol-4-monophosphate, glucose-6-phosphate, glutathione, and maltose were 
significantly high in BK01, while threonine, citric acid, galactinol, pyrophosphate, and $\mathrm{N}$-acetylglutamate were significantly low in BK01 compared with SR8LDH. These results suggested that SR8LDH and BK01 have global metabolic differences, including sugar metabolism (glucose-6-phosphate and citric acid), lipid biosynthesis (inositol-4monophosphate), amino acid biosynthesis (threonine and N-acetylglutamate), and stress response (glutathione).
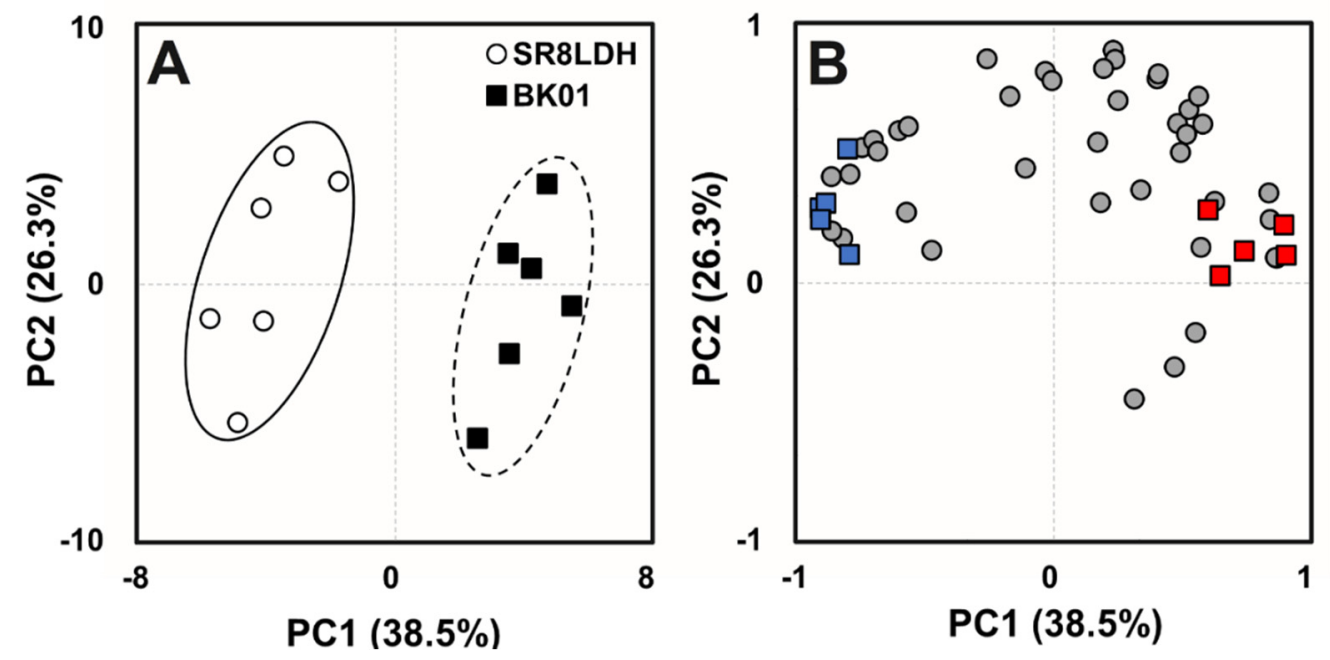

Figure 2. Principle component analysis of significantly different intracellular metabolomic profiles of SR8LDH and BK01 at a mid-exponential growth phase without lactic acid stress on (A) a score plot and (B) a loading plot. The colored metabolites indicate the five metabolites with the highest (red) and the lowest (blue) fold-change value among significantly different metabolites between SR8LDH and BK01. (Student's $t$-test, $p<0.05$ ), of which details can be found in Table S2. All cells were grown in complex medium containing $20 \mathrm{~g} / \mathrm{L}$ glucose, under oxygen-limited conditions ( $80 \mathrm{rpm}$ ), with an initial cell concentration of $0.5 \mathrm{~g}$ DCW/L.

\subsection{Lactic Acid Production by the Evolved Strain}

To determine whether lactic acid-tolerant BK01 could be a better lactic acid producer than SR8LDH, fermentation of a high glucose concentration $(200 \mathrm{~g} / \mathrm{L})$ was performed. Under such conditions, lactic acid can be accumulated at a level higher than $80 \mathrm{~g} / \mathrm{L}$, and $80 \mathrm{~g} / \mathrm{L}$ lactic acid is a critical concentration at which BK01 shows growth benefits. For this fermentation, no $\mathrm{pH}$-neutralizing agent was used. The rate of glucose consumption was similar between the two strains, although the maximum cell concentration was higher in SR8LDH (Figure 3A). The lower cell concentration of BK01 was not observed during low glucose fermentation (Figure S2). Meanwhile, the maximum lactic acid production of BK01 was $119.1 \mathrm{~g} / \mathrm{L}$, which was 17\% higher than SR8LDH (102.4 g/L) (Figure 3B). Ethanol was produced at $36.2 \mathrm{~g} / \mathrm{L}$ and $38.9 \mathrm{~g} / \mathrm{L}$ for BK01 and SR8LDH, respectively; thus, SR8LDH produced slightly more ethanol than BK01. When the mass balance of fermentation products (lactic acid, ethanol, and $\mathrm{CO}_{2}$ ) from glucose was calculated at $96 \mathrm{~h}$, BK01 showed a higher carbon recovery (93.7\%) than SR8LDH (86.0\%), which was consistent with higher cell growth in SR8LDH.

When lactic acid accumulated more than $100 \mathrm{~g} / \mathrm{L}$ during $200 \mathrm{~g} / \mathrm{L}$ glucose fermentation, the $\mathrm{pH}$ of the medium dropped to 3 (Figure S3), lower than its $\mathrm{pKa}$ value (3.86). Under such conditions, the lactic acid-tolerant BK01 strain showed higher lactic acid production than SR8LDH, and the highest reported titer ( $119 \mathrm{~g} / \mathrm{L}$ lactic acid) was achieved without $\mathrm{pH}$ control (Table 2).

The use of neutralizing agents, such as $\mathrm{Ca}(\mathrm{OH})_{2}$ and $\mathrm{CaCO}_{3}$, is currently necessary for industrial lactic acid production [23]. During re-acidification for purification of lactic acid, gypsum $\left(\mathrm{CaSO}_{4}\right)$ is produced as a byproduct, and additional processes and costs are required to remove this contaminant [43]. In addition, the huge amount of gypsum 
produced with the same mass as lactic acid causes serious environmental problems [43-45]. Alternatively, ammonia and ammonia hydroxide neutralizing agents are commonly used to avoid formation of gypsum, but they could decrease lactic acid titers because ammonium lactate produced during fermentation can cause osmotic stress to microbial cells [23]. Therefore, the use of a lactic acid-tolerant strain developed by ALE, such as BK01, could be a promising option for minimizing or excluding $\mathrm{pH}$ control for lactic acid bioprocesses.
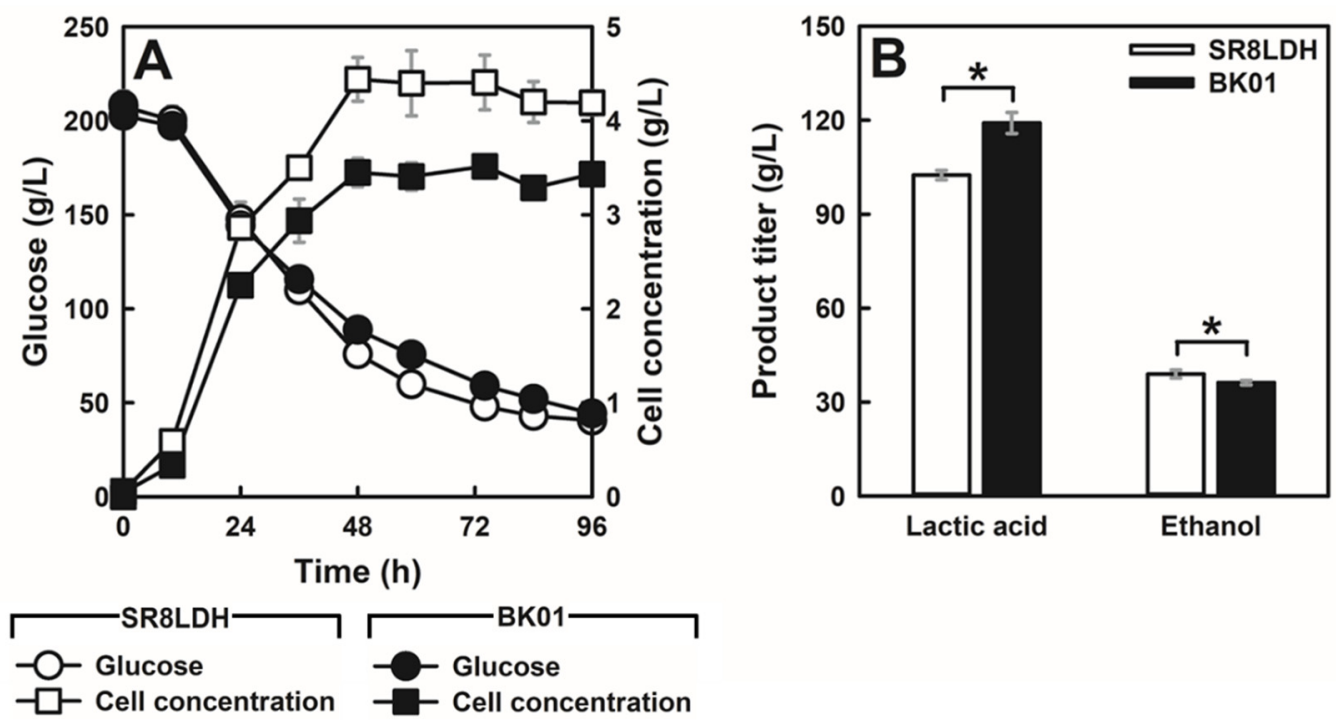

Figure 3. Comparison of lactic acid production by SR8LDH and BK01 in a high concentration of glucose. (A) Glucose (circle) and cell concentrations (square). (B) Lactic acid and ethanol titers for $96 \mathrm{~h}$ of fermentation. The values represent the mean of three independent experiments. The error bars indicate standard deviation. Asterisks denote statistically significant differences (Student's $t$-test, $p<0.05)$. Fermentations were performed using complex medium containing $200 \mathrm{~g} / \mathrm{L}$ glucose, under oxygen-limited conditions ( $80 \mathrm{rpm}$ ), with an initial cell concentration of $0.05 \mathrm{~g}$ DCW/L.

Table 2. Comparison of engineered S. cerevisiae strains producing lactic acid.

\begin{tabular}{|c|c|c|c|c|c|c|c|c|}
\hline Strain & $\begin{array}{c}L D H \\
\text { Origin }\end{array}$ & ALE & pH Control & $\mathrm{pH}$ & $\begin{array}{l}\text { Time } \\
\text { (h) }\end{array}$ & $\begin{array}{l}\text { Yield } \\
\text { (g/g) }\end{array}$ & $\begin{array}{l}\text { Titer } \\
\text { (g/L) }\end{array}$ & Reference \\
\hline$\delta \mathrm{pH} \delta \mathrm{LA} 2-51 / \mathrm{dP} 36$ & $L m$ & + & $20 \mathrm{~g} / \mathrm{L} \mathrm{CaCO}_{3}$ & 6.4 & 23 & 0.55 & 52 & [42] \\
\hline YPH499/dPdA3-34/DLDH/1-18 & $L m$ & - & $40 \mathrm{~g} / \mathrm{L} \mathrm{CaCO}_{3}$ & ND & 216 & 0.65 & 60 & [16] \\
\hline JHY5730 & $L m$ & + & $4 \mathrm{~N} \mathrm{NaOH}$ & 3.5 & 55 & 0.83 & 83 & [17] \\
\hline JHY5330 & $L m$ & - & $50 \mathrm{~g} / \mathrm{L} \mathrm{CaCO}_{3}$ & ND & 51 & 0.80 & 112 & [18] \\
\hline SP7 & Ps & - & Continuous & $3.5-6.0$ & 49 & 0.58 & 117 & [15] \\
\hline T165R & Bt & - & Unknown & 5.2 & 48 & 0.61 & 122 & [14] \\
\hline SP1130 & $P_{s}, B t$ & - & $5 \mathrm{~N} \mathrm{Ca}(\mathrm{OH})_{2}$ & 4.7 & 40 & 0.89 & 142 & [20] \\
\hline$\delta \mathrm{pH} \delta \mathrm{LA} 2-51 / \mathrm{dP} 36$ & $L m$ & + & None & ND & 52 & 0.30 & 34 & [42] \\
\hline SH6779 & $B t$ & - & None & ND & 72 & ND & 48 & [46] \\
\hline YIP-A15G12 & Ec & - & None & ND & 76 & 0.70 & 92 & [47] \\
\hline SR8LDH & $L a$ & - & None & ND & 96 & 0.61 & 102 & This study \\
\hline BK01 & $L a$ & + & None & ND & 96 & 0.72 & 119 & This study \\
\hline
\end{tabular}

Lm; Leuconostoc mesenteroides, Ps; Pelodiscus sinensis japonicas, Bt; Bos taurus, Ec; Escherichia coli, La; Lactobacillus acidophilus. ALE; adaptive laboratory evolution, ND; not determined, +; yes, -; no.

\subsection{Cellulosic Lactic Acid Production by the Evolved Strain}

To evaluate a potential to use BK01 for cellulosic lactic acid production, SSF was performed using buckwheat husk hydrolysates (Figure 4A). Buckwheat husk hydrolysates were prepared by dilute-acid pretreatment using $1 \%(w / v) \mathrm{H}_{2} \mathrm{SO}_{4}$ at $121{ }^{\circ} \mathrm{C}$ for $30 \mathrm{~min}$. At a high solid loading of the hydrolysates (20\%, dry weight basis), SR8LDH and BK01 showed similar fermentation profiles, with $\mathrm{pH}$ changes from 6.5 to 4.2 (Figure 4). During $24 \mathrm{~h}$, both glucose (50-55 g/L) and xylose (3-5 g/L) were consumed, and 32-34 g/L lactic acid was 
produced. On the other hand, the ethanol production of BK01 (17.6 g/L) was significantly higher than that of SR8LDH (14.4 g/L).

\section{A}
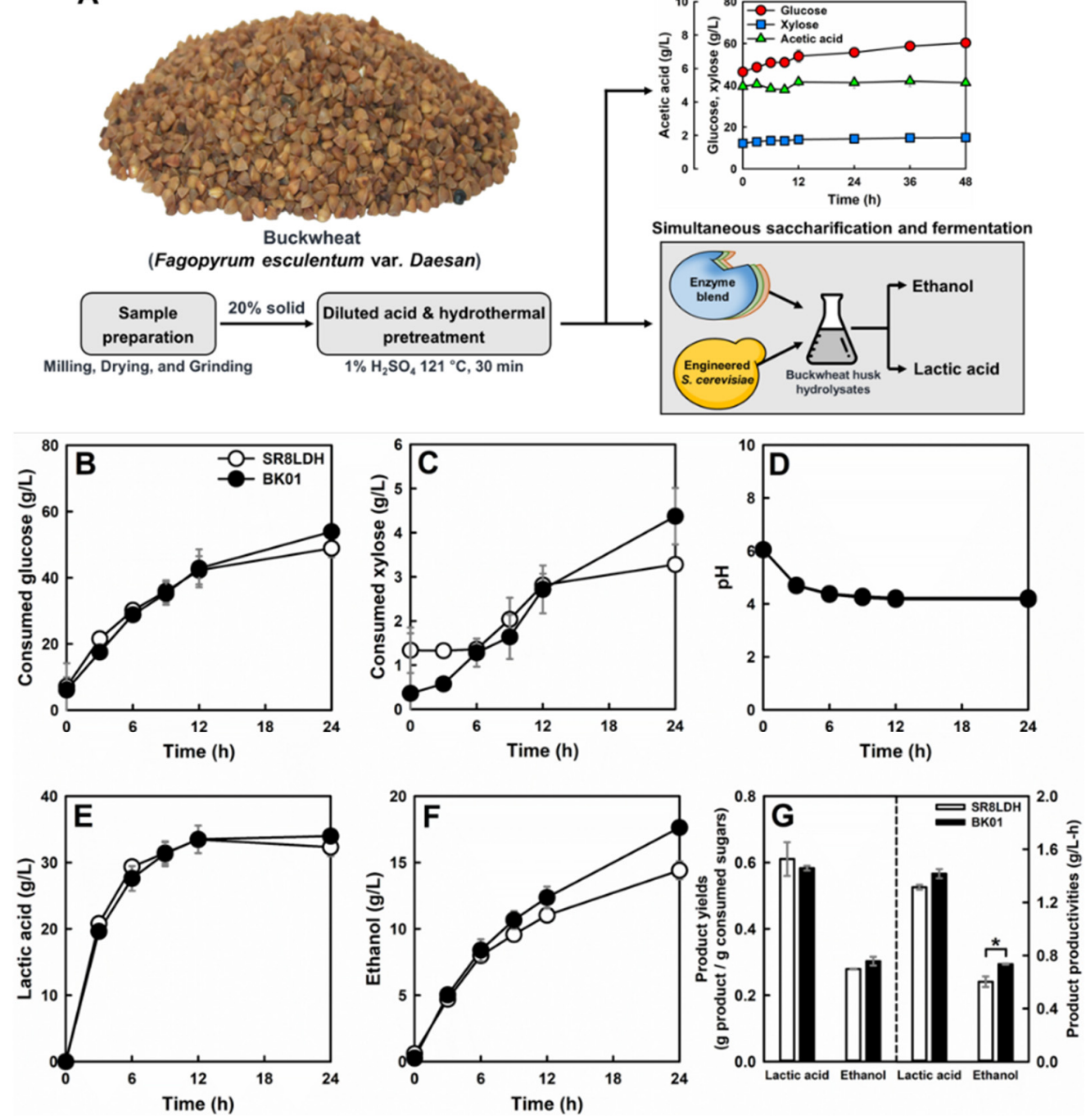

Figure 4. Cellulosic lactic acid production by SR8LDH and BK01 from simultaneous saccharification and fermentation of buckwheat husk hydrolysates (A). Consumed glucose (B), consumed xylose (C), $\mathrm{pH}(\mathbf{D})$, lactic acid (E), ethanol (F), and productivities (G) were compared. Values represent the mean of three independent experiments. Error bars indicate standard deviation. Asterisks denote statistically significant differences (Student's $t$-test, $p<0.05$ ).

Because the fermentation of $20 \%$ buckwheat husk hydrolysates did not accumulate lactic acid to its toxic level $(8 \%)$, BK01 might have a higher tolerance to fermentation inhibitors in the hydrolysates. Acetic acid is one of the important fermentation inhibitors of cellulosic biomass hydrolysates [48,49], and $20 \%$ buckwheat husk hydrolysates contains $5.3 \mathrm{~g} / \mathrm{L}$ acetic acid. As the fermentation progressed, lactic acid was accumulated, and the $\mathrm{pH}$ of the cellulosic biomass hydrolysates dropped from 6.5 to 4.2 . At this low $\mathrm{pH}$ (lower than the pKa value of acetic acid, 4.75), acetic acid would be the most critical inhibitor of cellulosic fermentation. Therefore, it was speculated that the improved cellulosic ethanol production by BK01 might be associated with improved acetic acid tolerance. Comparison of SR8LDH and BK01 on $20 \mathrm{~g} / \mathrm{L}$ glucose supplemented with $4 \mathrm{~g} / \mathrm{L}$ acetic acid confirmed that BK01 has a higher tolerance to acetic acid than SR8LDH (Figure S4). The cell growth, lactic acid production, and ethanol production of BK01 were significantly better than SR8LDH under the acetic acid stress. 
Lactic acid production by engineered S. cerevisiae was demonstrated mostly using complex and synthetic medium [50], and cellulosic lactic acid production was reported only in a few recent studies $[8,51]$. Using spent coffee ground hydrolysates and wheat straw hydrolysates, $11.5 \mathrm{~g} / \mathrm{L}$ [8] and $10 \mathrm{~g} / \mathrm{L}$ [51] lactic acid were produced. The increases in media potassium $\left(\mathrm{K}^{+}\right)$and $\mathrm{pH}$ were able to improve cellulosic lactic acid production significantly [51]. Additionally, the overexpression of GRE2 with detoxifying activity toward fermentation inhibitors in cellulosic biomass hydrolysates (furfural and hydroxymethylfurfural) contributed to further improvement in cellulosic lactic acid production. Therefore, the cellulosic lactic acid production by acid-tolerant BK01 is expected to be enhanced by the optimization of cellulosic medium compositions and further strain engineering for other stress tolerance.

\section{Conclusions}

The lactic acid-producing S. cerevisiae strain was subjected to ALE with a high concentration of lactic acid, and a lactic acid-tolerant BK01 strain was successfully isolated. Mutations responsible for the improved lactic acid tolerance of BK01 could not be identified from genome re-sequencing and reverse engineering, which suggests complex molecular mechanisms of the lactic acid tolerance. Meanwhile, BK01 showed distinct metabolomic profiles compared with its parental strain without lactic acid stress, suggesting a global metabolic shift by the evolution. Lactic-acid tolerant BK01 was able to score the highest lactic acid production $(119 \mathrm{~g} / \mathrm{L})$ from glucose without the use of a $\mathrm{pH}$-neutralizing agent. Interestingly, BK01 showed improved tolerance to acetic acid as well, which contributed to improved fermentation of acetate-rich lignocellulosic biomass hydrolysates. These results suggest that (1) ALE is a useful tool for developing complex traits of industrial interest, (2) lactic acid tolerance significantly improves lactic acid production, and (3) lactic acid tolerance might contribute to tolerance against other organic acids, including acetic acid.

Supplementary Materials: The following are available online at https: / www.mdpi.com/article / 10.3390/jof7110928/s1, Figure S1: Comparison of volumetric growth rates (g/L) of the reverse engineered strains from SR8LDH and BK01 in complex medium containing $20 \mathrm{~g} / \mathrm{L}$ glucose and $8 \%$ lactic acid, Figure S2: Fermentation profiles of the SR8LDH and BK01 strain in complex medium containing $20 \mathrm{~g} / \mathrm{L}$ glucose, Figure S3: Fermentation profiles of the BK01 strain in complex medium containing $200 \mathrm{~g} / \mathrm{L}$ glucose under oxygen-limited conditions ( $80 \mathrm{rpm})$ with initial cell concentration of $10 \mathrm{~g}$ DCW/L (g dry cell weight/L), Figure S4: Comparison of volumetric growth rates (g/L-h) of the SR8LDH and BK01 strains in complex containing $20 \mathrm{~g} / \mathrm{L}$ glucose and 2-5 g/L acetic acid, Table S1: Unique, non-synonymous SNPs in the parental and evolved strain, Table S2: Guide RNA structure, Table S3: Primers, Table S4: List of identified intracellular metabolites in SR8LDH and BK01.

Author Contributions: Conceptualization, S.-K.J., C.-K.K., Y.-S.C., and S.-R.K.; methodology, B.-K.J., Y.J., D.J., and S.-R.K.; software, B.-K.J.; validation, B.-K.J., C.-K.K., and Y.-S.C.; formal analysis, B.-K.J. and S.-R.K.; investigation, Y.J. and D.J.; data curation, S.-R.K.; resources, Y.-S.C.; writing-original draft preparation, B.-K.J. and S.-R.K.; writing—review and editing, S.-K.J., C.-K.K., Y.-S.C., and S.-R.K.; visualization, B.-K.J., Y.J., D.J., and Y.-S.C.; supervision, Y.-S.C., and S.-R.K.; project administration, Y.-S.C. and S.-R.K.; funding acquisition, S.-R.K. All authors have read and agreed to the published version of the manuscript.

Funding: This work was carried out with the support of "Cooperative Research Program for Agriculture Science and Technology Development (Project No. PJ01577003)" Rural Development Administration, Korea.

Institutional Review Board Statement: Not applicable.

Informed Consent Statement: Not applicable.

Data Availability Statement: Publicly available datasets were analyzed in this study. The data can be found here: https://www.ncbi.nlm.nih.gov/bioproject/PRJNA690663.

Conflicts of Interest: The authors declare no conflict of interest. 


\section{References}

1. Esteban, J.; Ladero, M. Food waste as a source of value-added chemicals and materials: A biorefinery perspective. Int. J. food Sci. Technol. 2018, 53, 1095-1108. [CrossRef]

2. Bustamante, D.; Tortajada, M.; Ramón, D.; Rojas, A. Production of D-Lactic Acid by the Fermentation of Orange Peel Waste Hydrolysate by Lactic Acid Bacteria. Fermentation 2020, 6, 1. [CrossRef]

3. Jamshidian, M.; Tehrany, E.A.; Imran, M.; Jacquot, M.; Desobry, S. Poly-lactic acid: Production, applications, nanocomposites, and release studies. Compr. Rev. food Sci. food Saf. 2010, 9, 552-571. [CrossRef] [PubMed]

4. Singhvi, M.; Zinjarde, S.; Gokhale, D. Polylactic acid: Synthesis and biomedical applications. J. Appl. Microbiol. 2019, 127, 1612-1626. [CrossRef] [PubMed]

5. Sohn, Y.J.; Kim, H.T.; Jo, S.Y.; Song, H.M.; Baritugo, K.-A.; Pyo, J.; Choi, J.-i.; Joo, J.C.; Park, S.J. Recent Advances in Systems Metabolic Engineering Strategies for the Production of Biopolymers. Biotechnol. Bioprocess Eng. 2020, 25, 848-861. [CrossRef]

6. Sauer, M.; Porro, D.; Mattanovich, D.; Branduardi, P. Microbial production of organic acids: Expanding the markets. Trends Biotechnol. 2008, 26, 100-108. [CrossRef]

7. Ghaffar, T.; Irshad, M.; Anwar, Z.; Aqil, T.; Zulifqar, Z.; Tariq, A.; Kamran, M.; Ehsan, N.; Mehmood, S. Recent trends in lactic acid biotechnology: A brief review on production to purification. J. Radiat. Res. Appl. Sci. 2014, 7, 222-229. [CrossRef]

8. Kim, J.-w.; Jang, J.H.; Yeo, H.J.; Seol, J.; Kim, S.R.; Jung, Y.H. Lactic acid production from a whole slurry of acid-pretreated spent coffee grounds by engineered Saccharomyces cerevisiae. Appl. Biochem. Biotechnol. 2019, 189, 206-216. [CrossRef]

9. Miller, C.; Fosmer, A.; Rush, B.; McMullin, T.; Beacom, D.; Suominen, P. Industrial production of lactic acid. Compr. Biotechnol. 2011, 3, 179-188.

10. Kong, X.; Zhang, B.; Hua, Y.; Zhu, Y.; Li, W.; Wang, D.; Hong, J. Efficient L-lactic acid production from corncob residue using metabolically engineered thermo-tolerant yeast. Bioresour. Technol. 2019, 273, 220-230. [CrossRef]

11. Ishida, N.; Suzuki, T.; Tokuhiro, K.; Nagamori, E.; Onishi, T.; Saitoh, S.; Kitamoto, K.; Takahashi, H. D-Lactic acid production by metabolically engineered Saccharomyces cerevisiae. J. Biosci. Bioeng. 2006, 101, 172-177. [CrossRef] [PubMed]

12. Eş, I.; Mousavi Khaneghah, A.; Barba, F.J.; Saraiva, J.A.; Sant' Ana, A.S.; Hashemi, S.M.B. Recent advancements in lactic acid production-A review. Food Res. Int. 2018, 107, 763-770. [CrossRef]

13. Kim, S.-K.; Auh, J.-H. Evaluating the Engineered Saccharomyces cerevisiae With High Spermidine Contents for Increased Tolerance to Lactic, Succinic, and Malic Acids and Increased Xylose Fermentation. Biotechnol. Bioprocess Eng. 2021, 26, 47-54. [CrossRef]

14. Saitoh, S.; Ishida, N.; Onishi, T.; Tokuhiro, K.; Nagamori, E.; Kitamoto, K.; Takahashi, H. Genetically engineered wine yeast produces a high concentration of L-lactic acid of extremely high optical purity. Appl. Environ. Microbiol. 2005, 71, $2789-2792$. [CrossRef] [PubMed]

15. Lee, J.Y.; Kang, C.D.; Lee, S.H.; Park, Y.K.; Cho, K.M. Engineering cellular redox balance in Saccharomyces cerevisiae for improved production of L-lactic acid. Biotechnol. Bioeng. 2015, 112, 751-758. [CrossRef]

16. Yamada, R.; Wakita, K.; Mitsui, R.; Ogino, H. Enhanced d-lactic acid production by recombinant Saccharomyces cerevisiae following optimization of the global metabolic pathway. Biotechnol. Bioeng. 2017, 114, 2075-2084. [CrossRef]

17. Baek, S.H.; Kwon, E.Y.; Bae, S.J.; Cho, B.R.; Kim, S.Y.; Hahn, J.S. Improvement of d-lactic acid production in Saccharomyces cerevisiae under acidic conditions by evolutionary and rational metabolic engineering. Biotechnol. J. 2017, 12, 1700015. [CrossRef]

18. Baek, S.-H.; Kwon, E.Y.; Kim, Y.H.; Hahn, J.-S. Metabolic engineering and adaptive evolution for efficient production of D-lactic acid in Saccharomyces cerevisiae. Appl. Microbiol. Biotechnol. 2016, 100, 2737-2748. [CrossRef] [PubMed]

19. Mimitsuka, T.; Sawai, K.; Kobayashi, K.; Tsukada, T.; Takeuchi, N.; Yamada, K.; Ogino, H.; Yonehara, T. Production of d-lactic acid in a continuous membrane integrated fermentation reactor by genetically modified Saccharomyces cerevisiae: Enhancement in d-lactic acid carbon yield. J. Biosci. Bioeng. 2015, 119, 65-71. [CrossRef]

20. Song, J.-Y.; Park, J.-S.; Kang, C.D.; Cho, H.-Y.; Yang, D.; Lee, S.; Cho, K.M. Introduction of a bacterial acetyl-CoA synthesis pathway improves lactic acid production in Saccharomyces cerevisiae. Metab. Eng. 2016, 35, 38-45. [CrossRef] [PubMed]

21. Turner, T.L.; Zhang, G.-C.; Kim, S.R.; Subramaniam, V.; Steffen, D.; Skory, C.D.; Jang, J.Y.; Yu, B.J.; Jin, Y.-S. Lactic acid production from xylose by engineered Saccharomyces cerevisiae without PDC or ADH deletion. Appl. Microbiol. Biotechnol. 2015, 99, 8023-8033. [CrossRef]

22. Park, H.J.; Bae, J.H.; Ko, H.J.; Lee, S.H.; Sung, B.H.; Han, J.I.; Sohn, J.H. Low-pH production of d-lactic acid using newly isolated acid tolerant yeast Pichia kudriavzevii NG7. Biotechnol. Bioeng. 2018, 115, 2232-2242. [CrossRef] [PubMed]

23. Singhvi, M.; Zendo, T.; Sonomoto, K. Free lactic acid production under acidic conditions by lactic acid bacteria strains: Challenges and future prospects. Appl. Microbiol. Biotechnol. 2018, 102, 5911-5924. [CrossRef]

24. Vaidya, A.; Pandey, R.; Mudliar, S.; Kumar, M.S.; Chakrabarti, T.; Devotta, S. Production and recovery of lactic acid for polylactide-an overview. Crit. Rev. Environ. Sci. Technol. 2005, 35, 429-467. [CrossRef]

25. Juturu, V.; Wu, J.C. Microbial production of lactic acid: The latest development. Crit. Rev. Biotechnol. 2016, 36, 967-977. [CrossRef] [PubMed]

26. Peetermans, A.; Foulquié-Moreno, M.R.; Thevelein, J.M. Mechanisms underlying lactic acid tolerance and its influence on lactic acid production in Saccharomyces cerevisiae. Microb Cell 2021, 8, 111-130. [CrossRef]

27. Jang, B.-K.; Jeong, D.; Seol, J.; Lee, Y.-K.; Kim, S.R. Xylose Facilitates Lactic Acid Yield of Engineered Saccharomyces cerevisiae. KSBB J. 2020, 35, 129-134. [CrossRef] 
28. Jang, J.; Ju, Y.; Lee, Y.-K.; Seol, J.; Kim, S.R. Production of Lactic Acid by Simultaneous Saccharification and Fermentation of Sargassum horneri. KSBB J. 2021, 36, 118-122. [CrossRef]

29. Kim, S.R.; Skerker, J.M.; Kang, W.; Lesmana, A.; Wei, N.; Arkin, A.P.; Jin, Y.-S. Rational and evolutionary engineering approaches uncover a small set of genetic changes efficient for rapid xylose fermentation in Saccharomyces cerevisiae. PLoS ONE 2013, 8, e57048. [CrossRef]

30. Lane, S.; Xu, H.; Oh, E.J.; Kim, H.; Lesmana, A.; Jeong, D.; Zhang, G.; Tsai, C.-S.; Jin, Y.-S.; Kim, S.R. Glucose repression can be alleviated by reducing glucose phosphorylation rate in Saccharomyces cerevisiae. Sci. Rep. 2018, 8, 1-12. [CrossRef] [PubMed]

31. Xu, H.; Kim, S.; Sorek, H.; Lee, Y.; Jeong, D.; Kim, J.; Oh, E.J.; Yun, E.J.; Wemmer, D.E.; Kim, K.H. PHO13 deletion-induced transcriptional activation prevents sedoheptulose accumulation during xylose metabolism in engineered Saccharomyces cerevisiae. Metab. Eng. 2016, 34, 88-96. [CrossRef]

32. Shin, M.; Kim, J.-w.; Ye, S.; Kim, S.; Jeong, D.; Lee, D.Y.; Kim, J.N.; Jin, Y.-S.; Kim, K.H.; Kim, S.R. Comparative global metabolite profiling of xylose-fermenting Saccharomyces cerevisiae SR8 and Scheffersomyces stipitis. Appl. Microbiol. Biotechnol. 2019, 103, 5435-5446. [CrossRef] [PubMed]

33. Jeong, D.; Oh, E.J.; Ko, J.K.; Nam, J.-O.; Park, H.-S.; Jin, Y.-S.; Lee, E.J.; Kim, S.R. Metabolic engineering considerations for the heterologous expression of xylose-catabolic pathways in Saccharomyces cerevisiae. PLoS ONE 2020, 15, e0236294. [CrossRef] [PubMed]

34. Kim, S.; Lee, D.Y.; Wohlgemuth, G.; Park, H.S.; Fiehn, O.; Kim, K.H. Evaluation and optimization of metabolome sample preparation methods for Saccharomyces cerevisiae. Anal. Chem. 2013, 85, 2169-2176. [CrossRef] [PubMed]

35. Ahn, J.K.; Kim, J.; Cheong, Y.E.; Kim, K.H.; Cha, H.S. Variation in the synovial fluid metabolome according to disease activity of rheumatoid arthritis. Clin. Exp. Rheumatol. 2020, 38, 500-507.

36. Furukawa, K.; Toyomizu, M.; Kikusato, M. Possible role of corticosterone in proteolysis, glycolytic, and amino acid metabolism in primary cultured avian myotubes incubated at high-temperature conditions. Domest. Anim. Endocrinol. 2021, 76, 106608. [CrossRef]

37. Lai, Z.; Tsugawa, H.; Wohlgemuth, G.; Mehta, S.; Mueller, M.; Zheng, Y.; Ogiwara, A.; Meissen, J.; Showalter, M.; Takeuchi, K. Identifying metabolites by integrating metabolome databases with mass spectrometry cheminformatics. Nat. Methods 2018, 15, 53-56. [CrossRef] [PubMed]

38. Ringnér, M. What is principal component analysis? Nat. Biotechnol. 2008, 26, 303-304. [CrossRef]

39. Park, H.; Park, S.U.; Jang, B.K.; Lee, J.J.; Chung, Y.S. Germplasm evaluation of Kenaf (Hibiscus cannabinus) for alternative biomass for cellulosic ethanol production. GCB Bioenergy 2021, 13, 201-210. [CrossRef]

40. Abbott, D.A.; Suir, E.; van Maris, A.J.; Pronk, J.T. Physiological and transcriptional responses to high concentrations of lactic acid in anaerobic chemostat cultures of Saccharomyces cerevisiae. Appl. Environ. Microbiol. 2008, 74, 5759-5768. [CrossRef]

41. Graves, T.; Narendranath, N.V.; Dawson, K.; Power, R. Effect of pH and lactic or acetic acid on ethanol productivity by Saccharomyces cerevisiae in corn mash. J. Ind. Microbiol. Biotechnol. 2006, 33, 469. [CrossRef]

42. Mitsui, R.; Yamada, R.; Matsumoto, T.; Yoshihara, S.; Tokumoto, H.; Ogino, H. Construction of lactic acid-tolerant Saccharomyces cerevisiae by using CRISPR-Cas-mediated genome evolution for efficient d-lactic acid production. Appl. Microbiol. Biotechnol. 2020, 104, 9147-9158. [CrossRef]

43. Pal, P.; Sikder, J.; Roy, S.; Giorno, L. Process intensification in lactic acid production: A review of membrane based processes. Chem. Eng. Process. Process. Intensif. 2009, 48, 1549-1559. [CrossRef]

44. Kumar, A.; Thakur, A.; Panesar, P.S. Lactic acid and its separation and purification techniques: A review. Rev. Environ. Sci. Bio/Technol. 2019, 18, 823-853. [CrossRef]

45. Dusselier, M.; Van Wouwe, P.; Dewaele, A.; Makshina, E.; Sels, B.F. Lactic acid as a platform chemical in the biobased economy: The role of chemocatalysis. Energy Environ. Sci. 2013, 6, 1415-1442. [CrossRef]

46. Suzuki, T.; Sakamoto, T.; Sugiyama, M.; Ishida, N.; Kambe, H.; Obata, S.; Kaneko, Y.; Takahashi, H.; Harashima, S. Disruption of multiple genes whose deletion causes lactic-acid resistance improves lactic-acid resistance and productivity in Saccharomyces cerevisiae. J. Biosci. Bioeng. 2013, 115, 467-474. [CrossRef] [PubMed]

47. Zhong, W.; Yang, M.; Hao, X.; Sharshar, M.M.; Wang, Q.; Xing, J. Improvement of D-lactic acid production at low pH through expressing acid-resistant gene IoGAS1 in engineered Saccharomyces cerevisiae. J. Chem. Technol. Biotechnol. 2020. [CrossRef]

48. Palmqvist, E.; Hahn-Hägerdal, B. Fermentation of lignocellulosic hydrolysates. I: Inhibition and detoxification. Bioresour. Technol. 2000, 74, 17-24. [CrossRef]

49. Ko, J.K.; Enkh-Amgalan, T.; Gong, G.; Um, Y.; Lee, S.M. Improved bioconversion of lignocellulosic biomass by Saccharomyces cerevisiae engineered for tolerance to acetic acid. GCB Bioenergy 2020, 12, 90-100. [CrossRef]

50. Baptista, S.L.; Costa, C.E.; Cunha, J.T.; Soares, P.O.; Domingues, L. Metabolic engineering of Saccharomyces cerevisiae for the production of top value chemicals from biorefinery carbohydrates. Biotechnol. Adv. 2021, 107697. [CrossRef]

51. Lam, F.H.; Turanl1-Yıldız, B.; Liu, D.; Resch, M.G.; Fink, G.R.; Stephanopoulos, G. Engineered yeast tolerance enables efficient production from toxified lignocellulosic feedstocks. Sci. Adv. 2021, 7, eabf7613. [CrossRef] 